\title{
Effects of Desipramine and Chlorimipramine on Buprenorphine Analgesia in Mice
}

\author{
Abdulrahman M. AGEEL \\ Department of Pharmacology. College of Pharmacy, King Saud University. \\ P.O. Box 2457, Riyadh-11451, Saudi Arabia \\ Accepted February 8, 1986
}

\begin{abstract}
The effects of the tricyclic antidepressants desipramine $\mathrm{HCl}$ and chlorimipramine $\mathrm{HCl}$ on buprenorphine $\mathrm{HCl}$ antinociceptive activity were studied in mice using the hot-plate and the tail-flick methods. In the hot-plate test, desipramine caused a transient antinociceptive effect at low doses, but it decreased buprenorphine analgesia. Chlorimipramine in this test caused a more sustained antinociceptive effect, especially at relatively higher doses, and it did not significantly change buprenorphine analgesia. In the tail-flick test, desipramine either reduced or increased the tail-flick latency in a dose-specific manner, and chlorimipramine $(10 \mathrm{mg} / \mathrm{kg})$ significantly increased the tail-flick latency. Desipramine $(1 \mathrm{mg} / \mathrm{kg})$ caused a decrease followed by an increase in buprenorphine analgesia. Desipramine ( 5 and $10 \mathrm{mg} / \mathrm{kg}$ ) caused significant increases in buprenorphine analgesia. All doses of chlorimipramine $(1,5$ and $10 \mathrm{mg} / \mathrm{kg}$ ) caused significant increases in buprenorphine analgesia. Thus, depending on the test employed, buprenorphine analgesia was modified differently by these tricyclics. Biochemical data suggested a greater role for brain 5 -hydroxytryptamine $(5-\mathrm{HT})$ than noradrenaline in tricyclic analgesia.
\end{abstract}

The relationship of brain monoamines to the 'analgesic' effect of morphine has been widely investigated. Of the biogenic amines, 5 - HT brain levels have been implicated in morphine analgesia (1-3). Some other investigators, however, were of the opinion that the brain catecholamines may modify morphine analgesia (4, 5). Various surgical, pharmacological electrophysiological and dietary manipulations of brain monoamines have been employed to elucidate the possible role of them in analgesia. One of the pharmacological methods which has been employed is the use of monoamine reuptake inhibitors in the brain. Indeed, there is some evidence that tricyclic antidepressants may induce analgesia (6) at low doses (7). Of the tricyclics, desipramine inhibits noradrenaline reuptake, and chlorimipramine inhibits 5-HT reuptake (8). Thus, they could be used as tools to examine directly the role of the brain monoamines uptake on analgesia.

Buprenorphine is a relatively new analgesic whose interactions with other drugs were scarcely investigated. It is $20-80$ times more potent than morphine and 120-550 times more potent than pentazocine as analgesic in animals (9). It is an antagonist qualitatively different from nalorphine and pentazocine. It shows greater resemblance to morphine than these agents (9).

It is felt that information about the interactions between buprenorphine and tricyclic antidepressants is needed. For this reason, the effects of desipramine and chlorimipramine on buprenorphine analgesia in the mouse were investigated.

\section{Materials and Methods}

Male albino mice ( $30-35 \mathrm{~g}$ ) obtained from King Saud University, College of Pharmacy Colony, were used. Analgesia was measured by two methods:

a) The hot-plate method: Analgesia was measured by the hot-plate reaction time test of Eddy and Leimbach (10). The hot-plate 
was hollow metal which was uniformly heated by water from a thermostatically controlled water bath. The hot-plate surface was kept at $55 \pm 0.5^{\circ} \mathrm{C}$. The animals were placed individually on the hot-plate, and the reaction time to the noxious stimulus was measured. Licking of paws or jumping was taken as the end point. A cut-off reaction time of $30 \mathrm{sec}$ was used in order to avoid tissue injury. Reaction time was measured for all animals, $15 \mathrm{~min}$ before any drug treatment; the mean reaction time was considered as $100 \%$, and reaction time after drug treatment was calculated relative to this value. The animals which scored a control reaction time of more than $10 \mathrm{sec}$ were not used. Reaction times were obtained $15 \mathrm{~min}$ after drug administration and thereafter at intervals of $30 \mathrm{~min}$. Groups of 8 animals were used.

b) The tail-flick method: The method employed was basically that of D'Amour and Smith (11). The tail-flick analgesimeter (Model DS 20. Apelex, France) is basically a source of heat (100 watt bulb). It concentrates a light beam onto the sensitive surface of a photocell by means of a parabolic reflector. The tail of an unrestrained animal was placed on the sensitive surface of the photocell. When the animal flicks its tail away from the photocell, the light beam goes off. The time from placing the animal's tail on the sensitive surface of the photocell till it was flicked was considered as the tail flick latency. A $30 \mathrm{sec}$ cut-off time was used to preclude tissue damage. Measurement of tail flick latency was performed $15 \mathrm{~min}$ before drug administration and 45, 75 and $105 \mathrm{~min}$ after its administration. Groups of 6 animals were used.

\section{Tissue determinations}

Tissue monoamines were determined by the spectrophotofluorimetric method of Welch and Welch (12). Individual whole mouse brains or spinal cords were assayed, using the same aliquot of homogenate for the two monoamines noradrenaline and 5-HT. Animals were treated with drug or saline, and subjects were killed by decapitation $105 \mathrm{~min}$ after drug treatments. The brain or the spinal cord were rapidly exposed and removed and frozen with Histo-Freeze (pure fluorocarbon12 (dichlorodifluoromethane), Fisher brand) for subsequent amine determinations.

\section{Drugs}

Drugs used were buprenorphine hydrochloride (Reckit and Colman), desipramine hydrochloride (Ciba-Geigy) and chlorimipramine hydrochloride (Ciba-Geigy). All drugs were dissolved in saline. Doses were expressed as the salt. The tricyclics were given by the i.p. route; and wherever applicable, they were given half an hour before buprenorphine. The latter drug was injected s.c.

\section{Statistical analysis}

The Mann-Whitney $U$-test was used for the analysis of the data of analgesia experiments. Student's $t$-test was used for tissue determinations experiments.

\section{Results}

\section{The antinociceptive effects of desipramine $\mathrm{HCl}$, chlorimipramine $\mathrm{HCl}$ and buprenorphine $\mathrm{HCl}$}

a) The hot-plate test: Control reaction time was found to be $8.7 \pm 0.3 \mathrm{sec}$ (mean \pm S.E. for 128 animals). Of the 3 doses of desipramine tested, the doses of 1 and $5 \mathrm{mg} / \mathrm{kg}$ caused a significant increase in reaction time as compared with saline-treated controls at 105 min following their administration to mice

$$
\begin{aligned}
& \text { O Saline } \\
& \square \text { Desipramine, } 1 \mathrm{mg} / \mathrm{kg} \\
& \triangle \text { Desipramine, } 5 \mathrm{mg} / \mathrm{kg} \\
& \times \text { Desipramine, } 10 \mathrm{mg} / \mathrm{kg}
\end{aligned}
$$

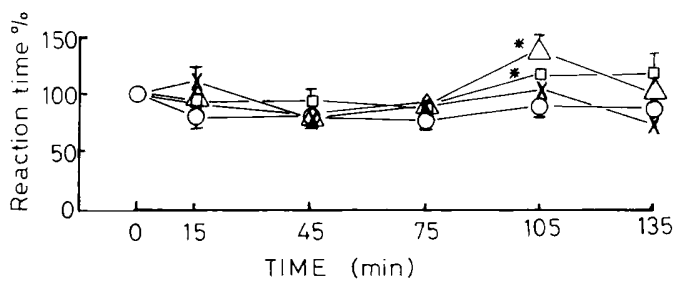

Fig. 1. Time-effect curves of desipramine $\mathrm{HCl}$ in the mouse hot-plate test. Mice were given desipramine $(1,5$ or $10 \mathrm{mg} / \mathrm{kg}$, i.p.) or saline (same dose volume $/ \mathrm{kg}$, i.p.) at time $0 \mathrm{~min}$. \% reaction time was calculated as described in 'Materials and Methods'. Each point represents the mean of 8 mice \pm S.E. $\left({ }^{*}\right)$ Indicates a significant difference between the drug-treated and control groups at the indicated interval at $\mathrm{P}<0.05$. 
(Fig. 1). Desipramine at $10 \mathrm{mg} / \mathrm{kg}$, however, did not cause any increase in reaction time throughout the $135 \mathrm{~min}$ observation period following its administration.

Chlorimipramine at 5 and $10 \mathrm{mg} / \mathrm{kg}$ showed significant antinociceptive effects at 105 and 135 min after its administration (Fig. $2)$. The smaller dose of $1 \mathrm{mg} / \mathrm{kg}$ was only significantly effective at $135 \mathrm{~min}$ after its administration.

Figure 3 shows the effects of $0.5,1$ and 2 $\mathrm{mg} / \mathrm{kg}$ buprenorphine on the hot-plate
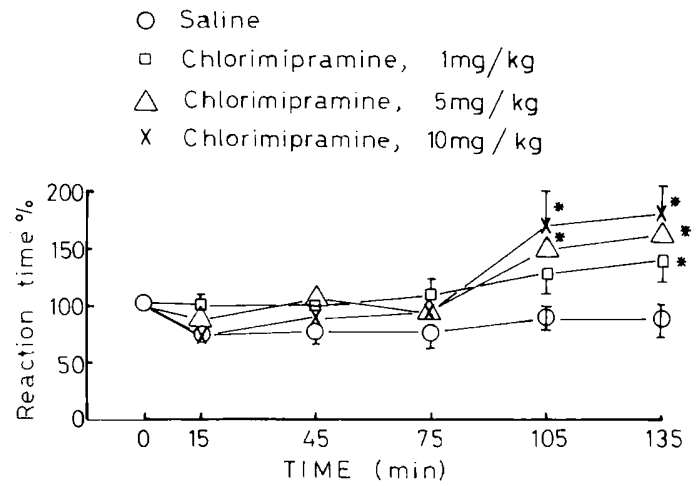

Fig. 2. Time-effect curves of chlorimipramine $\mathrm{HCl}$ in the mouse hot-plate test. Mice were given chlorimipramine (1.5 or $10 \mathrm{mg} / \mathrm{kg}$. i.p.) or saline (same dose volume $/ \mathrm{kg}$, i.p.) at time $0 \mathrm{~min}$. Other details as in Fig. 1. reaction time. A clear-cut antinociceptive effect started at $15 \mathrm{~min}$ after its administration and was persistent throughout the $2 \mathrm{hr}$ thereafter. Except for the smaller dose of $0.5 \mathrm{mg} / \mathrm{kg}$, the peak of the antinociceptive effect appeared $75 \mathrm{~min}$ after buprenorphine administration.

b) The tail-flick test: Desipramine $(1 \mathrm{mg} /$ $\mathrm{kg}$ ) did not affect the tail flick latency (Table $1)$. The other two doses of desipramine

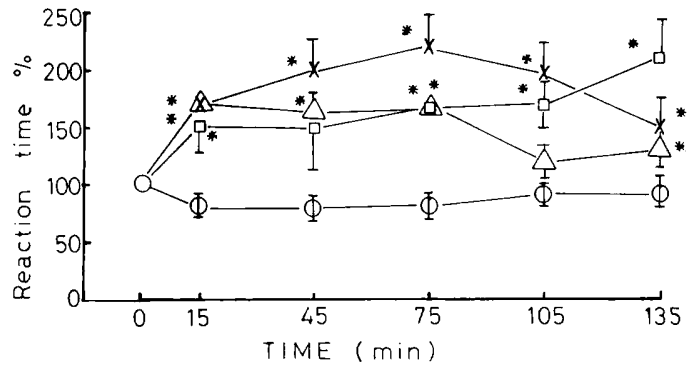

Fig. 3. Time-effect curves of buprenorphine $\mathrm{HCl}$ in the mouse hot-plate test. Buprenorphine $(0.5,1$ and $2 \mathrm{mg} / \mathrm{kg}$, s.c.) or saline were given at time $0 \mathrm{~min}$. Other details as in Fig. 1.

Table 1. Antinociceptive activity of desipramine $\mathrm{HCl}$, chlorimipramine $\mathrm{HCl}$ and buprenorphine $\mathrm{HCl}$ in mice using the tail-flick method

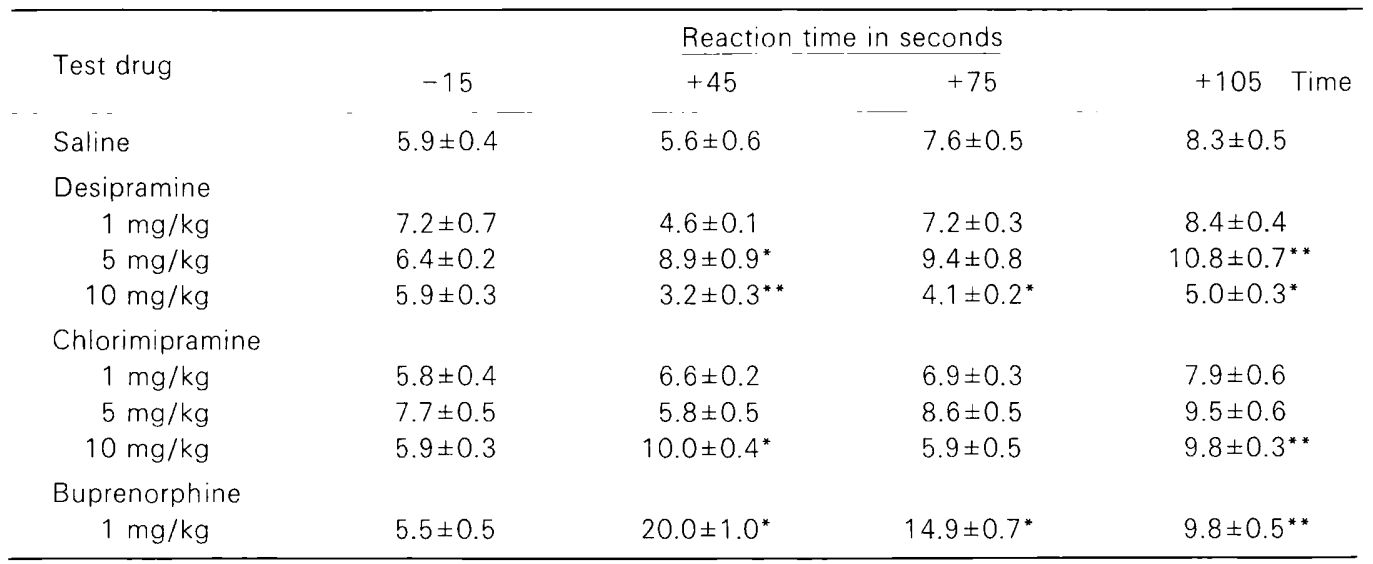

Time (in $\mathrm{min}$ ) in relation to the start of experiment. Each value represents the mean $\pm S$.E. for each group $(n=6)$. Test drug was injected at time 0 min. ${ }^{*} P<0.01$, as compared to saline. ${ }^{*} P<005$, as compared to saline. 
caused opposite effects since a significant increase in tail flick latency was seen at the dose of $5 \mathrm{mg} / \mathrm{kg}$ at 45 and $105 \mathrm{~min}$ after its administration, whereas $10 \mathrm{mg} / \mathrm{kg}$ desipramine caused a significant decrease in tail-flick latency throughout the $105 \mathrm{~min}$ obseravtion period. Chlorimipramine was only effective at the higher dose of $10 \mathrm{mg} / \mathrm{kg}$ which caused a significant increase in tail-flick latency at 45 and 105 min after its administration. Buprenorphine, as was expected, caused a marked antinociceptive effect in this test. being most effective at $45 \mathrm{~min}$ after its administration.

The antinociceptive effect of buprenorphine (1 $\mathrm{mg} / \mathrm{kg}$ ) after pretreatment with desipramine

a) The hot-plate test: The interactions between buprenorphine $(1 \mathrm{mg} / \mathrm{kg})$ and desipramine $(1,5$ and $10 \mathrm{mg} / \mathrm{kg}$ ) in the hot-plate reaction time test are shown in Fig. 4. It is clear that the smaller dose of desipramine $(1 \mathrm{mg} / \mathrm{kg})$ significantly reduced the antinociceptive activity of buprenorphine $45 \mathrm{~min}$ after its administration. Also, the dose of $5 \mathrm{mg} / \mathrm{kg}$ significantly reduced the antinociceptive activity of buprenorphine, but only at $105 \mathrm{~min}$, i.e., $75 \mathrm{~min}$ after buprenorphine administration (time of its peak effect). However, desipramine $(10 \mathrm{mg} / \mathrm{kg})$, which was without antinociceptive activity of its own, showed the greatest reduction in buprenorphine antinociceptive activity, namely, at time-intervals of 45, 75 and 105 $\min$.

b) The tail-flick test: Table 2 shows the results of the interaction between desipramine and buprenorphine using the tail-flick test. It is clearly seen that the results are in contrast to the findings of the hot-plate test. Pretreatment with $1 \mathrm{mg} / \mathrm{kg}$ desipramine caused a decrease in buprenorphine antinociceptive effect $75 \mathrm{~min}$ after desipramine administration, and this was followed by a significant increase in buprenorphine analgesia $30 \mathrm{~min}$ later. The other two doses of desipramine caused marked increases in

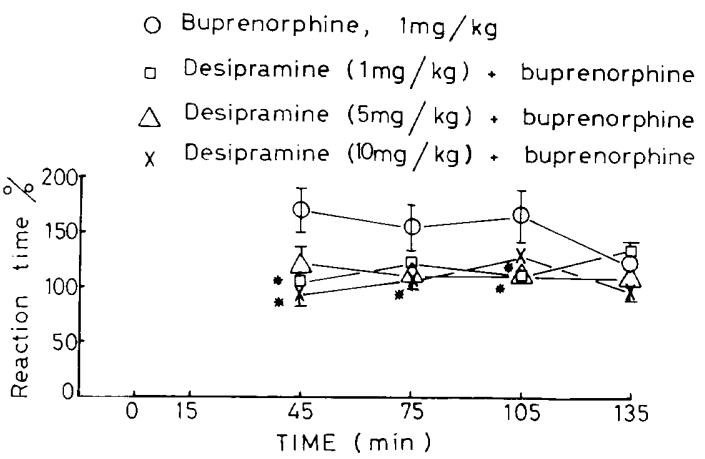

Fig. 4. Effects of desipramine (1,5 and $10 \mathrm{mg} / \mathrm{kg}$. i.p.) on buprenorphine (1 $\mathrm{mg} / \mathrm{kg}$, s.c.) analgesia. Desipramine was given at time $0 \mathrm{~min}$, and buprenorphine was injected at time $30 \mathrm{~min}$. Other details as in Fig. 1.

Table 2. Antinociceptive activity of buprenorphine $\mathrm{HCl}(1 \mathrm{mg} / \mathrm{kg})$ after pretreatment with desipramine $\mathrm{HCl}$ and chlorimipramine $\mathrm{HCl}$ in mice, using the tail-flick method

\begin{tabular}{|c|c|c|c|c|}
\hline \multirow{2}{*}{ Test drug } & \multicolumn{4}{|c|}{ Reaction time in seconds } \\
\hline & -15 & +45 & +75 & +105 \\
\hline $\begin{array}{l}\text { Saline } \\
\text { pretreatment }\end{array}$ & $5.8 \pm 0.4$ & $11.1 \pm 1.0$ & $21.8 \pm 2.4$ & $14.7 \pm 0.9$ \\
\hline \multicolumn{5}{|c|}{ Desipramine pretreatment } \\
\hline $1 \mathrm{mg} / \mathrm{kg}$ & $7.2 \pm 0.8$ & $10.2 \pm 0.5$ & $10.1 \pm 0.5^{*}$ & $24.3 \pm 1.8^{*}$ \\
\hline $5 \mathrm{mg} / \mathrm{kg}$ & $5.4 \pm 0.2$ & $23.8 \pm 2.2^{*}$ & $29.7 \pm 0.3^{* *}$ & $26.6 \pm 1.7^{* *}$ \\
\hline $10 \mathrm{mg} / \mathrm{kg}$ & $6.6 \pm 0.2$ & $23.2 \pm 1.6^{*}$ & $26.2 \pm 1.4$ & $30.0 \pm 0.0^{*}$ \\
\hline \multicolumn{5}{|c|}{ Chlorimipramine pretreatment } \\
\hline $1 \mathrm{mg} / \mathrm{kg}$ & $6.6 \pm 0.7$ & $20.8 \pm 1.5^{*}$ & $30.0 \pm 0.0^{* *}$ & $30.0 \pm 0.0^{*}$ \\
\hline $5 \mathrm{mg} / \mathrm{kg}$ & $7.4 \pm 0.8$ & $30.0 \pm 0.0^{*}$ & $30.0 \pm 0.0^{* *}$ & $30.0 \pm 0.0^{*}$ \\
\hline $10 \mathrm{mg} / \mathrm{kg}$ & $6.2 \pm 0.5$ & $30.0 \pm 0.0^{*}$ & $30.0 \pm 0.0^{* *}$ & $30.0 \pm 0.0^{*}$ \\
\hline
\end{tabular}

Time (in $\mathrm{min}$ ) in relation to the start of experiment. Each value represents the mean \pm S.E. for each group $(n=6)$. Pretreatments were given at time $0 \mathrm{~min}$, and buprenorphine was injected at time $30 \mathrm{~min}$ in all pretreated groups. ${ }^{*} \mathrm{P}<0.01$, as compared to saline. ${ }^{*} \mathrm{P}<0.05$, as compared to saline. 
the antinociceptive effect of buprenorphine, especially at the time interval of $105 \mathrm{~min}$.

The antinociceptive effect of buprenorphine (1 $\mathrm{mg} / \mathrm{kg}$ ) after pretreatment with chlorimipramine

a) The hot-plate test: Chlorimipramine at $1 \mathrm{mg} / \mathrm{kg}$ and $5 \mathrm{mg} / \mathrm{kg}$ prior to buprenorphine administration significantly reduced the antinociceptive effect of buprenorphine at 105 and $45 \mathrm{~min}$ intervals, respectively (Fig. 5). The higher dose of $10 \mathrm{mg} / \mathrm{kg}$ did not affect the antinociceptive activity of buprenorphine.

b) The tail-flick test: As seen from Table 2, chlorimipramine caused marked increases in the antinociceptive effect of buprenorphine at all doses tested and at all time intervals. In most cases, the animals reached the predetermined cut-off time without sensation

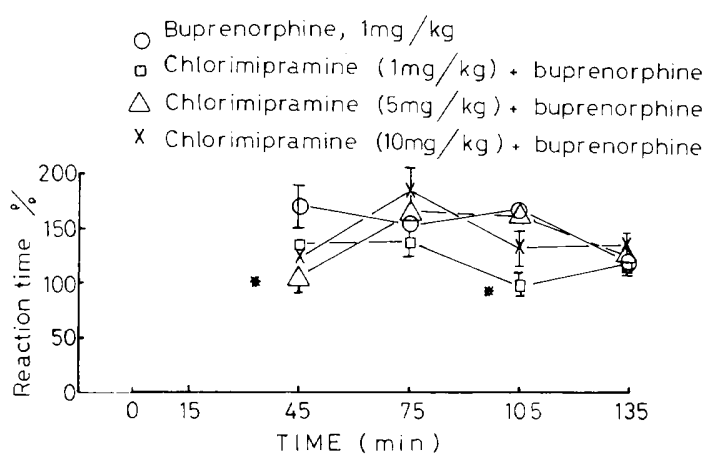

Fig. 5. Effects of chlorimipramine (1, 5 and 10 $\mathrm{mg} / \mathrm{kg}$, i.p.) on buprenorphine (1 $\mathrm{mg} / \mathrm{kg}$, s.c.) analgesia. Chlorimipramine was given at $0 \mathrm{~min}$ and buprenorphine was injected at time $30 \mathrm{~min}$. Other details as in Fig. 1. of the noxious stimulus.

\section{Tissue monoamines}

Table 3 summarizes the effect of desipramine and chlorimipramine on the monoamine content of mouse whole brain and spinal cord. Only the higher dose of desipramine (i.e., $10 \mathrm{mg} / \mathrm{kg}$ ) caused a significant rise in brain noradrenaline level. The same dose caused a significant fall in spinal cord noradrenaline content. Desipramine, however, was without any effect on 5-HT content in either tissue.

Chlorimipramine, on the other hand, affected only 5 - HT content, and this was only observed at the dose of $10 \mathrm{mg} / \mathrm{kg}$ which caused a significant rise in the brain but not the spinal cord content of this monoamine.

\section{Discussion}

The results of the present study demonstrate that the tricyclic antidepressants desipramine and chlorimipramine affect nociception in mice. Both drugs increased the hot-plate reaction time, but desipramine in a higher dose of $10 \mathrm{mg} / \mathrm{kg}$ did not significantly increase the hot-plate reaction time. In the tail-flick test, pain perception was reduced by $5 \mathrm{mg} / \mathrm{kg}$ desipramine, but it was increased by the higher dose of $10 \mathrm{mg} / \mathrm{kg}$, and $1 \mathrm{mg} / \mathrm{kg}$ desipramine did not affect the tail-flick latency. Chlorimipramine on the other hand, exerted a significant antinociceptive effect in the latter test, only at the higher dose of 10 $\mathrm{mg} / \mathrm{kg}$. Thus it appears that the tricyclics possess an antinociceptive effect of their own. Desipramine analgesia was seen at relatively small doses, and it disappeared or

Table 3. Effect of desipramine and chlorimipramine on monoamine content of mouse whole brain and spinal cord

\begin{tabular}{|c|c|c|c|c|c|}
\hline \multirow{2}{*}{ Treatment } & \multirow{2}{*}{$\begin{array}{l}\text { Dose } \\
\mathrm{mg} / \mathrm{kg}\end{array}$} & \multicolumn{2}{|c|}{$\begin{array}{l}\text { Whole brain } \\
\mu \mathrm{g} / \mathrm{g} \text { tissue } \pm \text { S.E. }(n=6)\end{array}$} & \multicolumn{2}{|c|}{$\begin{array}{l}\text { Spinal cord } \\
\mu \mathrm{g} / \mathrm{g} \text { tissue } \pm \text { S.E. }(n=3)\end{array}$} \\
\hline & & Noradrenalene & $5-\mathrm{HT}$ & Noradrenaline & $5-\mathrm{HT}$ \\
\hline Saline & - & $0.315 \pm 0.024$ & $0.589 \pm 0.026$ & $0.257 \pm 0.033$ & $0.173 \pm 0.023$ \\
\hline \multirow[t]{3}{*}{ Desipramine $\mathrm{HCl}$} & 1 & $0.340 \pm 0.032$ & $0.619 \pm 0.020$ & $0.237 \pm 0.031$ & $0.186 \pm 0.028$ \\
\hline & 5 & $0.336 \pm 0.023$ & $0.656 \pm 0.026$ & $0.225 \pm 0.021$ & $0.168 \pm 0.021$ \\
\hline & 10 & $0.498 \pm 0.019^{*}$ & $0.671 \pm 0.034$ & $0.168 \pm 0.018^{* *}$ & $0.187 \pm 0.017$ \\
\hline \multirow[t]{3}{*}{ Chlorimipramine $\mathrm{HCl}$} & 1 & $0.340 \pm 0.023$ & $0.623 \pm 0.058$ & $0.263 \pm 0.035$ & $0.161 \pm 0.026$ \\
\hline & 5 & $0.361 \pm 0.036$ & $0.672 \pm 0.055$ & $0.206 \pm 0.024$ & $0.158 \pm 0.020$ \\
\hline & 10 & $0.410 \pm 0.041$ & $0.786 \pm 0.030^{*}$ & $0.181 \pm 0.014$ & $0.149 \pm 0.012$ \\
\hline
\end{tabular}

Levels were measured 105 min after drug administration.

${ }^{*} \mathrm{P}<0.01$, as compared to saline. ${ }^{* *} P<0.05$, as compared to saline. 
reversed at a higher dose of $10 \mathrm{mg} / \mathrm{kg}$. Chlorimipramine analgesia was clearly observed at the higher dose of $10 \mathrm{mg} / \mathrm{kg}$. though it was also seen at the smaller doses used in this study by using the hot-plate test. The results of this study are in contrast to the findings of Gonzalez et al. (13) and Spencer (1) who either could not demonstrate or only observed only a weak antinociceptive activity of the tricyclics in mice. Differences in results could be attributed to the use of different testing procedures, different strains of mice, different laboratories and many other factors.

There was also some evidence that 5-HT plays a more significant role on analgesia than noradrenaline. Desipramine (noradrenaline reuptake inhibitor) caused a transient antinociceptive effect at low doses in the hotplate test. This effect was not observed after a relatively higher dose of $10 \mathrm{mg} / \mathrm{kg}$ and was even reversed in the tail-flick test. Chlorimipramine (5-HT reuptake inhibitor), on the other hand, caused an antinociceptive effect which was more sustained than that of desipramine. Chlorimipramine antinociceptive activity was more prominent at relatively higher doses. Moreover, fluoxetine (5-HT reuptake inhibitor) has previously been shown to induce analgesia (14). The biochemical results demonstrated that the brain level of noradrenaline was increased by desipramine $(10 \mathrm{mg} / \mathrm{kg})$ whilst chlorimipramine $(10 \mathrm{mg} /$ $\mathrm{kg}$ ) increased the brain level of $5-\mathrm{HT}$. This supports the idea that tryptaminergic mechanisms in the brain play an important role in analgesia. The spinal cord monoamine levels are not a sufficient prerequisite for tricyclic analgesia as it appeared from the results of the present study. Spinal cord noradrenaline was decreased by the dose of desipramine that either did not affect nociception in the hotplate test or increased it in the tail-flick test. Also, this dose of desipramine caused opposite effects on noradrenaline levels in the brain and the spinal cord, whereas chlorimipramine was without any effect on spinal cord 5-HT level, though it has affected the brain content of this monoamine.

Considering the interaction between the tricyclics and buprenorphine, it was found that the tricyclics decreased buprenorphine analgesia when the hot-plate test was used, but they potentiated buprenorphine analgesia in the tail-flick test. Exceptions to these findings were desipramine $(1 \mathrm{mg} / \mathrm{kg})$, which either caused a decrease followed by an increase in tail flick latency, and chlorimipramine $(10 \mathrm{mg} / \mathrm{kg})$, which did not change the hot-plate reaction time. The results of the tail-flick test were what was expected because both the tricyclics and buprenorphine possess analgesic activity; and predictably, the concurrent administration of either of the tricyclics with buprenorphine should have an additive effect or cause potentiation of the tail-flick latency. The discrepancies between the results of the two tests are not easy to explain. It has been indicated that the mouse hot-plate test does not consistently respond to any drug group except the opiate narcotic agonists (1). Also, since the opiate analgesics may also exert antidepressant activity (15), an exaggerated antidepressant effect may have resulted from the tricyclic-buprenorphine combination which caused the animals to be aware of the source of the noxious stimulus in the hot-plate test and hence they jumped up once they were placed on the hot-plate. This perhaps was not the case in the tail-flick test where animals were not able to see the source of the noxious stimulus which was subjected only onto their tails.

Like buprenorphine, the analgesic action of morphine (16) and of methadone (17) have been reported to be potentiated with desipramine, but the analgesic action of pentazocine was not potentiated by this tricyclic (13). The potentiation of the analgesic action of methadone was attributed to inhibition of its metabolism by desipramine (17). It is probable that the same mechanism may be responsible for the potentiation of buprenorphine analgesia by the tricyclic, and this is now under investigation at this institute.

It can be concluded from the present study that tricyclic drugs exert an antinociceptive effect of their own and that the 5-HT reuptake inhibitor chlorimipramine has a more pronounced antinociceptive effect than the noradrenaline reuptake inhibitor decipramine. Both tricyclics potentiate desipramine analgesia, and once again, chlorimipramine has a greater effect in that 
respect than desipramine. The tricyclics have been used to relieve depression accompanying pain. The results of this study suggest that the tricyclics which inhibit $5-\mathrm{HT}$ reuptake could be more useful in relieving pain than those which inhibit noradrenaline reuptake when they are used in conjunction with buprenorphine.

\section{References}

1 Spencer, P.S.J.: Some aspects of the pharmacology of analgesia. J. Int. Med. Res. 4, 1-14 (1976)

2 Messing, R.B. and Lytle, L.C.: Serotonincontaining neurons; their possible role in pain and analgesia. Pain 4, 1-21 (1977)

3 Fuller, R.W.: Pharmacology of central serotonin neurons. Annu. Rev. Pharmacol. Toxicol. 20, 111-127 (1980)

4 Major, C.T. and Pleuvry, B.J.: Effects of $\alpha$ methyl-p-tyrosine, $p$-chlorophenylalanine, L- $\beta$ (3.4-dihydroxyphenyl)alanine, 5-hydroxytryptophan and diethyldithiocarbamate on the analgesic activity of morphine and methylamphetamine in the mouse. Br. J. Pharmacol. 42, 512-521 (1971)

5 Nakamura, K., Kuntzman, R., Maggio, A.C., Augulis, V. and Conney, A.H.: Influence of 6 hydroxydopamine on the effect of morphine on the tail-flick latency. Psychopharmacology (Berlin) 31, 177-189 (1973)

6 Paoli, F., Dacourt, G. and Cossa, P.: Note preliminaire sur l'action de l'imipramine dans les etats douloureux. Rev. Neurol. (Paris) 102, 503 (1960)

7 zur Daxelmuller, L.: Therapic schwerer Schmerzzustande mit Tofranil. Med. Welt 43, 2339 (1966)

8 Marco, E.J. and Meek, J.L.: The effect of antidepressants on serotonin turnover in discrete regions of rat brain. Naunyn Schmiedebergs Arch. Pharmacol. 306, 75-79 (1979)

9 Lewis, J.W.: Buprenorphine-a new strong analgesic. In Problems in Pain, Edited by Peck. C. and Wallace, M., p. 87-89, Pergamon Press, Oxford (1980)

10 Eddy, N.B. and Leimbach, D.: Synthetic analgesics. II. Dithienylbutenyl- and dithienylbutylamines. J. Pharmacol. Exp. Ther. 107, 385-393 (1953)

11 D'Amour, F.E. and Smith, D.L.: A method for determining loss of pain sensation. J. Pharmacol. Exp. Ther. 72, 74-79 (1941)

12 Welch, A.S. and Welch, B.L.: Solvent extraction method for simultaneous determination of norepinephrine, dopamine, serotonin, and 5 hydroxyindoleacetic acid in a single mouse brain. Anal. Biochem. 30, 161-179 (1969)

13 Gonzalez, J.P., Lee, R.L., Sewell, R.D.E. and Spencer, P.S.J.: Antidepressants and pain: a review of some human and animal studies. In Nomifensine: Royal Society of Medicine International Congress and Symposium Series, No. 25. p. 59-69. Academic Press Inc. and the Royal Society of Medicine, London (1980)

14 Messing, R.B., Rhebus, L., Fisher, L. and Lytle, L.D.: Analgesic effect of fluoxetine $\mathrm{HCl}$ (Lilly 110-140), a specific uptake inhibitor for serotoninergic neurons. Psychopharmacol. Commun. 1, 511-521 (1975)

15 Doggett, N.S., Reno, H. and Spencer, P.S.J.: Narcotic agonist and antagonists as models for antidepressant drugs. Neuropharmacology 14 , 507-515 (1975)

16 Saarnivaara, L. and Mattila, M.J.: Comparison of tricyclic antidepressants in rabbits: Antinociception and potentiation of the noradrenaline pressor responses. Psychopharmacology (Berlin) 35, 221-236 (1974)

17 Liu, S. and Wang, R.I.H.: Increased methadone analgesia by desipramine in the rat and possible mechanism(s) involved. In Problems of Drug Dependence. Proceedings of the 37th Annual Scientific Meeting Committee on Problems of Drug Dependence, p. 678-689, Nationa! Academy of Sciences, Washington D.C. (1975)

\section{ERRATUM}

A.M. AGEEL: Vol. 41, No. 2, p. 139-145 (1986)

page 144, column 2, lines 4 and 3 from bottom. decipramine should read desipramine

page 144, column 2, lines 3 and 2 from bottom. desipramine should read buprenorphine 